\title{
Dr. Richard C. Nelson: Teacher, Researcher, Motivator, Leader, and Incredible Human
}

\author{
Kathryn Dainty Davis \\ Exponent, Inc
}

\begin{abstract}
As one of the early graduate students of the Penn State Biomechanics Laboratory (1970-1974), I had the pleasure of being involved in the lab developed under the direction of Dr. Richard Nelson. His vision of applying engineering principles to human movement, particularly through the vehicle of sport analysis, inspired many to commit to a career of biomechanical exploration of the many aspects of human movement. By bringing many international scholars to the lab, he exposed his students to innovative and unique approaches to research. By developing technical applications, he made biomechanical inquiry more scientific and applicable. By caring for and mentoring a new generation of scientists and providing them the direction and tools they would need to establish their own labs and careers, he helped us become teachers, researchers, consultants, and mentors for a new generation of students. His love of life inspired us all to further the groundbreaking work he had begun and continued throughout his amazing career. His contributions to the field of biomechanics through his visionary establishment of societies, journals, collegial relationships, and consulting skills have served our community well. It was an honor and a privilege to know and learn from him.
\end{abstract}

Keywords: innovator, mentor, scientist, consultant

While attending the University of Montana in 1969 to work on my master's degree, my advisor Dr. Brian Sharkey, who had just returned from a sabbatical leave at Penn State, told me of a new program in biomechanics at Penn State as I had expressed an interest in examining this discipline with respect to sport and physical activity. Dr. Sharkey introduced me to Dr. Nelson, who was immediately interested in having another Canadian in his lab as one of his first students, Dr. Doris Miller, was completing her doctorate and returning to Saskatchewan, even though there were others there as well. Dr. Nelson insisted that I have at least 1 year's professional experience before commencing my doctorate program, so after completing my master's degree, I returned to Toronto and taught high school for a year before heading to State College, Pennsylvania, to begin my doctoral program.

Upon arrival in State College, we were all introduced to the fabulous "Water Tower Biomechanics Laboratory" and met the faculty, staff, and old and new students. For me, this was the beginning of a 4-year adventure in academic studies, research, and teaching that would lay the foundation for my career and life's work. The pride, love, and humor with which Dick spoke of the lab established the manner in which we all performed in working on the many tasks assigned to us individually and collectively. As well as developing our teaching skills and the bases for many techniques and methodologies used in the study of human motion from a biomechanical perspective, Dick was also instrumental in encouraging and supporting the development of technical innovations along with the supporting staff, such as Ken Petak, John Palmgren, and the collective minds of the various students with complimentary backgrounds. This was at the very beginning of computer usage and information storage, manipulation, and processing.

While studying the engineering sciences as well as human anatomy and physiology, we had the opportunity to examine, in real time, how these studies could help us better understand human

Davis (kdavis@exponent.com) is with Exponent, Inc, Los Angeles, CA, USA. movement from a mechanical basis. With Dick, Dewey Morehouse, and soon to arrive, Peter Cavanagh showing me and my fellow students how to apply our newly learned knowledge, we began to understand the kinematics and kinetics of human movement through a vehicle we all loved, namely sport, as we were, after all, in the Department of Physical Education. By using the tools of high-speed photography, electromyography, anthropometrics, force plate technology, and rudimentary programming using our Hewlett Packard computer, we were able to examine movement parameters and the underlying force activation patterns, both internal and external, that created the motions we were studying. By laying this important groundwork at Penn State, many of us were able to go on and examine complex human movements in regard to sports analysis, ergonomics, equipment design from performance (shoes) through protection (helmets), and work with other scientists to help improve safety and basic understanding of function and response of many aspects of human movement. It was Dick Nelson who inspired and helped many of us to achieve this understanding through his encouragement and leadership and break many boundaries of research with innovative thought and hard work.

As the discipline of biomechanics grew, Dick made many more contributions with the establishment of societies, conferences, journals, and visiting professors and sending his students out to establish new programs and laboratories. It also allowed the science to expand into new areas of consultation for such disciplines as prosthetic design, helmet development to protect athletes in hockey, football, and other sports and undertakings, and eventually, into the area of forensic biomechanics. As the members of the discipline grew to understand the importance of injury causation and mitigation, a need arose to understand, from a legal perspective, the cause of a broad range of injuries due to physical insult to the various tissues of the body. As well, by examining the forces placed on the body during activities such as falling while walking, climbing and descending stairs, and tumbling from heights as well as forces due to movements in a vehicle when 
the motion is perturbed because of impacts or other events, the science of biomechanics was able to explain injury causation and assist the legal profession in determining where fault may or may not lie.

It was this latter development that allowed Dick to shine, once again, as an innovator in the advancement of biomechanics in the field of forensics. As an expert witness, he was able to teach juries about the intricacies of injury etiology in a manner that was both understandable and able to withstand the scrutiny of the legal, adversarial process. His role as a teacher, mentor, scientist, and conversationalist prepared him to address the biomechanical issues in over 500 cases during his consulting career, helping victims of many different types of accidents in their homes, at work, and during sporting activities receive the care and compensation they needed and deserved. I have been privileged to work as an expert witness for over 20 years, and certainly, many of the principles I apply today were learned in the biomechanics laboratory at Penn State with the mentorship of Dick and other faculty. Although techniques have changed, and understanding has advanced a great deal, the basic principles of biomechanics remain the same, and the understanding of the engineering sciences, anatomy, physiology, and measurement fundamentals developed and taught at the Biomechanics Lab still serve today. Thank you, Dr. Richard C. Nelson, for your contributions, your support, your humor, and your love of learning that have enriched my life and the lives of so many others. 